УДК 327.8

Виктор МИРОНЕНКО

\title{
«УКРАИНСКИЙ ТРАНЗИТ»: ПОПЫТКА АНАЛИЗА И ПРОГНОЗА
}

Аннотация. Автор на примере президентских выборов на Украине рассматривает направленность и темпь «украинского транзита» с использованием аналитической оптики, дающей возможность увидеть объективные условия, которые определяют его вероятные долгосрочные траектории. Такой непредвзятый объективный анализ с точки зрения автора может представлять научный интерес, поскольку помогает понять Украину, найти приемлемый для обеих сторон алгоритм межгосударственных отношений и использовать украинский опыт для выбора оптимальных моделей системной индивидуальной и сопряжённой с украинской модернизаџии российских общества и государства.

Ключевые слова: Россия, Украина, российско-украинские отношения, украинский кризис, украинский транзит, четвёртая украинская республика, сопряжённая модернизация.

Что показали президентские выборы на Украине? Ответы на этот вопрос будут, по-видимому, очень разными в зависимости от того, с какой целью и с какой точки зрения мы их рассматриваем, а также от того, какую аналитическую оптику мы используем. Подход может быть прагматическим или аналитическим. Оптика может быть - микроскопической или телескопической. В том, что пришлось прочесть или услышать об украинских выборах в обоих отношениях преобладает первая.

Анализ появившихся в России откликов на состоявшиеся, несмотря на имевшиеся в связи с введением в ряде областей Украины военного положения ${ }^{1}$ сомнения, шестые по счёту президентские выборы на Украине, даёт возможность к двум, предложенным Алексеем Миллером и чаще всего используемым при изучении «украинского вопроса» аналитическим оптикам - «телеологической» и конспирологической ${ }^{2}-$ добавить ещё одну - телескопическую.

Оперативному анализу уже подвергнуты нюансы предвыборной борьбы, её приемы, закулисные механизмы, выдвинуты гипотезы её последствий, «арьергардных боёв» и предстоящих осенью парламентских и в следующем 2020 г. местных выборов ${ }^{3}$.

(C) Мироненко Виктор Иванович - кандидат исторических наук, ведущий научный сотрудник, руководитель Центра украинских исследований Отдела страновых исследований ИЕ РАН. Адрес: 125009 , Россия, Москва, ул. Моховая, д. 11, стр. 3. E-mail: victor@mironenko.org.

DOI: http://dx.doi.org/10.15211/vestnikieran320195863

1 Появился текст указа Порошенко о военном положении на Украине. УНИAH. 26.11.2018. URL: https://www.unian.net/politics/10352859-poyavilsya-tekst-ukaza-poroshenko-o-voennom-polozhenii-v-ukraine.html.

2 Алексей Миллер. Россия и русификация Украины в XIX веке. 2018 г. URL: http://litopys.narod.ru/vzaimo/ vz12.htm (дата обращения: 12.07.2018).

${ }_{3}^{3}$ См.: Александр Гущин. Как избрание Зеленского президентом повлияет на будущий состав Рады. Независимая газета, 29.04.2019; Константин Скоркин. Как украинская элита готовится к поражению Порошенко. Московский Центр Карнеги, 12.04.2019. URL: https://carnegie.ru/commentary/78860; Фёдор Лукьянов. За пять лет стало понятно, что Евромайдан завершил европейскую либеральную революцию. Профиль. 25.02.2019. URL: https://profile.ru/politics/za-pyat-let-stalo-ponyatno-chto-evromajdan-zavershil-evropejskuyu-liberalnuyu-revolyuciyu68415/; Андрей Цыганков. Украина, Америка и «остров Россия». 29.03.2019, Валдай URL: http://ru.valdaiclub. com/a/highlights/ukraina-amerika-ostrov-rossiya/; «Для Кремля Зеленский крайне неприятная личность». Украина выбрала нового президента. К чему готовиться России? ZNAK, 22.04.2019. URL: https://www.znak.com/2019-0422/ukraina_vybrala novogo_prezidenta_k chemu_gotovitsya_rossii; «Сегодня на Украине не может быть президента, удобного для России». Аркадий Мошес - об украинских выборах и их влиянии на отношения Москвы и 
Добавить к этому что-либо трудно, но можно попытаться взглянуть на это событие более широко - ретроспективно и перспективно, так как оно выглядит в контексте «украинского транзита» в целом. А также, добавив ещё несколько событийных и смысловых точек, попробовать вычертить его дальнейшую вероятную траекторию.

\section{Результаты выборов и первая реакция на них.}

30 апреля Центральная избирательная комиссия на Украине объявила победителем шестых по счёту президентских выборов Владимира Зеленского. Явка избирателей во втором туре составила 61,37\%. Бюллетени получили 18 млн 409 тыс. 313 из 29 млн 645 тыс. 358 гра-ждан Украины, внесённых в списки. Согласно оглашённым ЦИК данным за него проголосовали 13541528 избирателей (73,22\% принявших участие в голосовании), а за Петра Порошенко - 4522450 человек $(24,45 \%)^{1}$.

По оценкам международных и украинских наблюдателей, обнародованным по итогам мониторинга избирательного процесса ${ }^{2}$, повторные выборы президента Украины были свободными и конкурентными, а наличествующие нарушения не влияют на их результат ${ }^{3}$.

3 мая результаты выборов были опубликованы в газете «Голос Украины» ${ }^{4}$. С этого момента новый президент считается избранным. 20 мая на торжественной церемонии инаугурации в Верховном Совете (Раде) Украины, Владимир Зеленский принёс присягу и вступил в должность 5 .

Политическая борьба, между тем, не прекращалась. На этот раз вокруг ожидавшегося роспуска парламента. В этой связи одни депутаты пытались упомянутую выше церемонию отодвинуть за временные рамки, допускающие такой шаг нового президента. Другие, наоборот, поддержать его в этом его прозрачном намерении. Так, например, 6 мая народный депутат Виктор Балога внёс ещё один законопроект с таким же предложением, зарегистрированный под номером 10270-1, заявив при этом, что «если новая команда желает как можно раньше начать работать, то в этом нет ничего плохого, даже если Зеленский хочет это сделать для того, чтобы иметь время распустить парламент» ${ }^{6}$.

В дискуссии вокруг сроков проведения инаугурации можно было легко рассмотреть одну из ключевых политических парадигм в новейшей истории Украины - колебания между режимами президентской и парламентской республики.

\section{Что показали президентские выборы на Украине}

В целом, результаты президентских выборов на Украине, как, впрочем, и многое другое

Киева. Коммерсант, 03.04.2019. URL: https://www.kommersant.ru/doc/3930298; Цедилина Елена. Пятилетие войны на Донбассе - перспективы мирного урегулирования. РСМД, 12.04.2019. URL: https://russiancouncil.ru/analytics-and-comments/interview/pyatiletie-voyny-na-donbasse-perspektivy-mirnogouregulirovaniya/ и др.

'Центральна виборча комісія України. Офіційний сайт. 30.04.2019. URL: https://www.cvk.gov.ua/info/protokol cvk 30042019.pdf (дата обращения: 07.05.2019).

${ }^{2}$ Российской Федерации в праве послать наблюдателей было отказано, как и в организации выборов на её территории для находящихся здесь граждан Украины. Это дало повод для критики с её стороны организации выборов, но вряд ли может поставить под сомнение их результаты.

${ }^{3}$ Who Is Supporting Ukraine's Top Presidential Candidates? 27.03.2019. By Kateryna Odarchenko URL: https://www. wilsoncenter.org/blog-post/who-supporting-ukraines-top-presidential-candidates.

${ }^{4}$ Щодо офіційного оголошення результатів чергових виборів Президента України 31 березня 2019 року. Голос України, 3 травня 2019 р.

5 Конституція України. Розділ V Стаття 104. URL: https://zakon.rada.gov.ua/laws/show/254\%D0\%BA/96$\% \mathrm{D} 0 \% \mathrm{~B} 2 \% \mathrm{D} 1 \% 80$.

${ }^{6}$ У ВР зареєстровано ще один проект постанови із датою інавгурації Зеленського. УHIAH, 07.05.2019. URL: https://www.unian.ua/politics/10540707-u-vr-zareyestrovano-shche-odin-proekt-postanovi-iz-datoyu-inavguraciji-ze lenskogo.html.

Научно-аналитический вестник ИЕ РАН, 2019, №3 
в её политической жизни, выглядят как вполне ожидаемые, и в то же время как совершенно неожиданные в зависимости от позиции наблюдателя и используемой им аналитической оптики.

Так, например, при использовании «короткой» аналитической оптики и результат первого тура и, тем более, результат второго тура выглядят неожиданными. В первом случае новичок в политике, не имевший, как утверждалось, сильной команды, Владимир Зеленский обошёл и политических «тяжеловесов», таких, как Юлия Тимошенко, и политических национал-популистов с большим опытом, как, например, Олег Ляшко. Во втором случае, ни в существующие представления о раскладе сил, ни в политические прогнозы не вписывался такой значительный разрыв в результатах голосования между действующим (чтобы там ни говорили его критики, довольно популярным в определённых слоях украинских социума и политикума) главой государства и политическим «парвеню», коим не без оснований считали его противника.

Но при смене «короткой» оптики на «длинную» всё становится на свои места и ясно видны обстоятельства, позволяющие считать результат обоих туров не только вполне объяснимым и объективно обоснованным, но и таким, который даёт возможность увидеть некоторые недавние повороты украинской политики под несколько иным углом зрения и по другому взглянуть на весь «постсоветский» «украинский транзит».

В том, что касается недавнего прошлого, период с середины 2012 по май 2014 г. и последовавшие за этим события (антитеррористическая операция, «гибридная война», военное положение, ограничения некоторых свобод и др.) в свете прошедших выборов и их результатов выглядят как вынужденное, спровоцированное в большей степени внешними обстоятельствами отклонение от общей политической парадигмы. В том числе и главной из них, отличающей Украину от многих других т.н. «новых независимых государств» Восточной Европы и Центральной Азии - решать политические (и не только политические) споры политическими же, правовыми средствами.

А в том, что касается будущего, эти выборы обозначили очередной исторический рубеж, пересечённый Украиной в её «суверенном цивилизационном транзите» - назад в Европу, в реальный мир, каким бы непривлекательным или опасным он кому-то не казался. В эту реальную Европу, в этот реальный мир, какими бы они ни были, Украина, похоже, готова идти, не оглядываясь на Россию, предоставив ей самой выбирать, собирается ли она идти вместе с Украиной «в Европу», оставаться на месте или идти в каком-то ином направлении.

На наш взгляд, значение президентских выборов 2019 г. состоит в том, что они, во-первых, состоялись, несмотря на продолжающуюся «гибридную войну» и тяжелейшее социально-экономическое положение (с крайне низкими в этой связи были более чем альтернативными; в третьих, они были прозрачными с перекрёстным контролем со стороны кандидатов и наблюдателей, с минимальными, как уже отмечалось, нарушениями и при отсутствии нарушений «системных», то есть, были Выборами (с большой буквы), а не их имитацией.

То, как прошла предвыборная кампания, выборы и их результаты, не могут не убедить любого непредвзятого наблюдателя в том, что на Украине есть гражданское общество. Оно, ещё очень слабо, болеет, но живо, взрослеет, набирается политического опыта и, в целом, когда ему такая возможность представляется, адекватно реагирует на вызовы времени и обстоятельства - внешние и внутренние.

Имея даже самое общее представление об этих вызовах и обстоятельствах, достаточно взглянуть на количество участников голосования и то, как разделились их голоса, чтобы убедиться: голосование объективно мотивировано, реакция адекватна. 
Первая часть «украинского транзита» успешно пройдена, хотя и не без потерь. На этом уже можно что-то строить. Это «что-то» мы бы определили как режим Четвёртой украинской республики ${ }^{1}$. Теперь предстоит научиться, простите за каламбур, адекватно реагировать на адекватную реакцию - предложить маршрут дальнейшего транзита, «склеить Украину» - консолидировать и мобилизовать жизнеспособную часть общества и начать двигаться в том направлении, которое эти выборы указали, как компас. И это, несомненно, путь «в Европу». Не географически, а политически. Украина готова к этому, её граждане в своём большинстве этого хотят.

Уверенности в том, что политический истеблишмент и политический класс в целом на Украине к этому готов, у нас нет. Как нет и уверенности в том, что к этому готов политический класс остальной Европы. Но есть уверенность в том, что с тем, как прошли президентские выборы на Украине в тяжелейший для неё исторический момент, всем, кто хотел этого, представилась возможность понять, в чём состоит категорический политический императив. Другого пути развязать европейский «гордиев узел», образовавшийся после ухода в Лету CССР, просто не существует. А не развязав его, не решить и внутренние проблемы, с которыми столкнулась Европа и что продемонстрировали состоявшиеся выборы в Европейский парламент.

\section{Заключение}

Итак, выводы из наблюдения и анализа результатов с использованием предложенной аналитической оптики украинских президентских выборов состоят в том, что:

- они ещё раз вполне определённо указали направление «украинского транзита» - европейское в самом широком и прямом смысле этого слова;

- пройдена, возможно, не самая трудная, но самая опасная часть пути;

- потери - территориальные и социальные, хозяйственные - велики, но не критичны;

- украинское общество научилось выживать за счёт природных и человеческих ресурсов в самых тяжёлых обстоятельствах.

Теперь в процессе «длинных» выборов - президентских, парламентских и местных, к которым стоит присмотреться особенно внимательно, как и ко всему активно идущему в тени больших политических баталий процессу децентрализации, предстоит предложить приемлемую для большинства модель Четвёртой украинской республики и заложить её правовой и политический фундамент.

Что касается реакции нашей российской администрации, она была замедленной и выжидательной ${ }^{2}$. Но, судя по косвенным свидетельствам, например по замене кураторов: Владислава Суркова на Михаила Бабича, отозванного из Минска ${ }^{3}$, и Олега Говоруна на Алексея Филатова ${ }^{4}$, в Кремле происходит некоторое переосмысление «украинской политики».

Как бы там ни было, результат выборов оказался неожиданным и даже шокирующим для многих и в Москве, и в Брюсселе, и в Вашингтоне 5

\footnotetext{
${ }^{1}$ В предлагаемой автором периодизации истории Украинской республики ей предшествовали три другие: первая (1917-1922), вторая (1918-1991) и третья (1991-2014).

2 «Для Кремля Зеленский крайне неприятная личность». Украина выбрала нового президента. К чему готовиться России? ZNAK, 22.04.2019. URL: https://www.znak.comukraina vybrala novogo prezidenta k chemu gotovitsya rossii (дата обращения: 06.05.2019).

YHIAH, 06.05.2019. URL: https://www.unian.ua/war/10539708-vatazhka-dnr-terminovo-viklikali-do-moskvizmi.html (дата обращения: 07.05.2019).

УHIAH, 05.04.2019. URL: https://www.unian.ua/war/10506204-glavoyu-upravlinnya-kremlya-shchodo-ukrajinistane-kurator-ldnr-zmi.html (дата обращения: 07.05.2019).

5 УHIAH, 10.04.2019. URL: https://www.unian.ua/world/10510902-derzhsekretar-ssha-nazvav-vidminnist-situaciy-zkrimom-i-golanskimi-visotami.html (дата обращения: 07.05.2019).
} 
Между тем советники новоизбранного украинского президента Александр Данилюк и Руслан Рябошапка поспешили в Брюссель, где обсудили, как утверждается, к очередному саммиту «Украина - ЕС», который должен состояться в июле. А комиссар Европейского союза по вопросам европейской политики соседства и переговоров о расширении Йоханес Хан, встретившись 7 мая с Владимиром Зеленским в Киеве, предложил ему совершить свой пер-вый зарубежный визит в Брюссель ${ }^{1}$, что он и сделал.

Значит ли это что-либо и что именно покажет время, но очевидно, что в этой печальной истории перевёрнута ещё одна страница, а новую, по-видимому, лучше писать без старых ошибок. Всё говорит о том, что время, отпущенное на них историей, заканчивается.

Ещё двумя подтверждениями сделанных нами выводов стали: первое - драматическая церемония инаугурации, состоявшаяся 20 мая, и речь на ней нового президента Украины; второе - статья известного именно своим «телескопическим», широким, если не сказать глобальным подходом к анализу текущих политических событий американского исследователя Френсиса Фукуямы, в которой он делает два неожиданных для американского учёного-эксперта утверждения. Во-первых, о том, что «Украина способна быть демократией» с реальной состязательной политикой и значительно улучшить реноме - своё и всей Восточной Европы. А во-вторых, что она сегодня является, возможно, полем битвы за либеральную демократию в Европе и за европейскую демократию для всего мира ${ }^{2}$.

Всё сказанное, на наш взгляд, является достаточным основанием, чтобы сменить аналитическую оптику в российских украинских исследованиях и прийти к выводу том, что национальным интересам России в большей мере отвечало бы не мешать Украине идти своим путём, на который она встала и, судя по всему, не намерена с него сходить. А может быть даже помочь ей в этом.

\section{Список литературы}

Александр Гущин. Как избрание Зеленского президентом повлияет на будущий состав Рады. Независимая газета, 29.04.2019 г.

Константин Скоркин. Как украинская элита готовится к поражению Порошенко. Московский Центр Карнеги, 12.04.2019. URL: https://carnegie.ru/commentary/78860 (дата обращения: 06.05.2019).

Фёдор Лукьянов. За пять лет стало понятно, что Евромайдан завершил европейскую либеральную революцию. Профиль, 25.02.2019. URL: https://profile.ru/politics/za-pyat-let-staloponyatno-chto-evromajdan-zavershil-evropejskuyu-liberalnuyu-revolyuciyu-68415/ (дата обращения: 06.05.2019).

Цедилина Елена. Пятилетие войны на Донбассе - перспективы мирного урегулирования. РСМД, 12.04.2019. URL: https://russiancouncil.ru/analytics-and-comments/interview/pyatiletievoyny-na-donbasse-perspektivy-mirnogo-uregulirovaniya/

Андрей Цыганков. Украина, Америка и «остров Россия». 29.03.2019, Валдай. URL: http:// ru.valdaiclub.com/a/highlights/ukraina-amerika-ostrov-rossiya (дата обращения: 06.05.2019).

«Сегодня на Украине не может быть президента, удобного для России». Аркадий Мошес - об украинских выборах и их влиянии на отношения Москвы и Киева. Коммерсант, 03.04.2019. URL: https://www.kommersant.ru/doc/3930298 (дата обращения: 06.05.2019).

\footnotetext{
1 УHIAH. URL: https://www.unian.ua/politics/10541601-yes-zaproponuvav-zelenskomu-zdiysniti-pershiy-vizit-dobryusselya.html.

${ }^{2}$ Francis Fukuyama. Why We Can't Get Enough of Ukraine Atlantic Council May 6, 2019 [On line]. URL: https:// www.atlanticcouncil.org/blogs/ukrainealert/why-we-can-t-get-enough-of-ukraine (дата обращения: 07.05.2019).
}

Научно-аналитический вестник ИЕ РАН, 2019, №3 


\section{References}

Francis Fukuyama. Why We Can't Get Enough of Ukraine Atlantic Council. 06.05.2019 [On line]. URL: https://www.atlanticcouncil.org/blogs/ukrainealert/why-we-can-t-get-enough-ofukraine (accessed date: 07.05.2019).

A comic is the favorite for Ukraine's next president. There's some good news in that. The Washington Post, 06.04.2019 [On line]. URL: https://www.washingtonpost.com/opinions/globalopinions/a-comic-is-the-favorite-for-ukraines-next-president-theres-some-good-news-in-that/2019/ 04/06/6c9fdeba-570e-11e9-8ef3-fbd41a2ce4d5_story.html (accessed date: 07.05.2019).

Who Is Supporting Ukraine's Top Presidential Candidates? 27.03.2019. By Kateryna Odarchenko [On line]. URL: https://www.wilsoncenter.org/blog-post/who-supporting-ukraines-toppresidenti al-candidates (accessible date: 06.05.2019).

Chris Miller. In Ukraine's Election, Pro-Russian Candidates Can't Win Foreign Policy. 04.04.2019 [On line]. URL: https://foreignpolicy.com/2019/04/04/in-ukraines-election-pro-russiancandidates-cant-win/ (accessible date: 07.05.2019).

Aleksandr Gushchin. Kak izbraniye Zelenskogo prezidentom povliyayet na budushchiy sostav Rady. Nezavisimaya gazeta, 29.04.2019.

Konstantin Skorkin. Kak ukrainskaya elita gotovitsya k porazheniyu Poroshenko Moskovskiy Tsentr Karnegi, 12.04.219. URL: https://carnegie.ru/commentary/78860 (дата обращения: 06.05.2019).

Fyodor Luk'yanov. Za pyat' let stalo ponyatno, chto Yevromaydan zavershil yevropeyskuyu liberal'nuyu revolyutsiyu. Profil', 25.02.2019. URL: https://profile.ru/politics/za-pyat-let-stalo-ponya tno-chto-evromajdan-zavershil-evropejskuyu-liberalnuyu-revolyuciyu-68415/ (дата обращения: 06.05.2019).

Tsedilina Yelena. Pyatiletiye voyny na Donbasse - perspektivy mirnogo uregulirovaniya. RSMD, 12.04.2019. URL: https://russiancouncil.ru/analytics-and-comments/interview/pyatiletievoyny-na-donbasse-perspektivy-mirnogo-uregulirovaniya/

Andrey Tsygankov. Ukraina, Amerika i «ostrov Rossiya». 29.03.2019, Valday. URL: http:// ru.valdaiclub.com/a/highlights/ukraina-amerika-ostrov-rossiya (дата обращения: 06.05.2019).

«Segodnya na Ukraine ne mozhet byt' prezidenta, udobnogo dlya Rossii». Arkadiy Moshes - ob ukrainskikh vyborakh i ikh vliyanii na otnosheniya Moskvy i Kiyeva. Kommersant, 03.04.2019. URL: https://www.kommersant.ru/doc/3930298 (дата обращения: 06.05.2019).

\section{«Ukrainian transit»: attempt of analysis and forecast}

Author: Victor Mironenko, Candidate of Sciences (History), Chief of the Centre for Ukrainian Studies of the Department of Countries Studies, Institute of Europe, Russian Academy of Sciences. Address: 113, Mokhovaya str., Moscow, Russia, 125009. E-mail: victor@mironenko.org.

Abstract. The author proposes to examine the direction and speed of «Ukrainian transit» on the example of the latest President elections in Ukraine, using the analitical optics, which gives the opportunity to notice its possible long-term trajectories, objective conditions, which determine them. Such an unprejudiced analysis from the point of view of the author may present some research interest, help to understand Ukraine and use the Ukrainian experience for choosing optimal models of systematic, individual and connected with Ukranian one modernisation of the Russian society and state.

Keywords: Russia, Ukraine, Russian-Ukrainian relations, Ukrainian crisis, Ukrainian transit, fourth Ukrainian Republic, coupled modernization, co-evolution.

DOI: http://dx.doi.org/10.15211/vestnikieran320195863 